Article

\title{
Structure-Based Design, Synthesis and Bioactivity of a New Anti-TNF $\alpha$ Cyclopeptide
}

\author{
Mohannad Idress ${ }^{1,2}{ }^{(0}$, Bruce F. Milne ${ }^{3}\left(\mathbb{0}\right.$, Gary S. Thompson ${ }^{4}\left(\mathbb{D}\right.$, Laurent Trembleau ${ }^{2}$, \\ Marcel Jaspars ${ }^{2}(\mathbb{D}$ and Wael E. Houssen $1,2, *$ (D) \\ 1 Institute of Medical Sciences, University of Aberdeen, Ashgrove Road West, Aberdeen AB25 2ZD, UK; \\ mohannad.idress@outlook.com \\ 2 Marine Biodiscovery Centre, Department of Chemistry, University of Aberdeen, Meston Walk, \\ Aberdeen AB24 3UE, UK; 1.trembleau@abdn.ac.uk (L.T.); m.jaspars@abdn.ac.uk (M.J.) \\ 3 CFisUC, Department of Physics, University of Coimbra, Rua Larga, 3004-516 Coimbra, Portugal; \\ bfmilne@gmail.com \\ 4 Wellcome Trust Biomolecular NMR Facility, School of Biosciences, University of Kent, Canterbury, Kent, \\ England CT2 7NZ, UK; g.s.thompson@kent.ac.uk \\ * Correspondence: w.houssen@abdn.ac.uk; Tel.: +44-(0)-122-443-7564
}

Received: 30 January 2020; Accepted: 14 February 2020; Published: 19 February 2020

\begin{abstract}
As opposed to small molecules, macrocyclic peptides possess a large surface area and are recognised as promising candidates to selectively treat diseases by disrupting specific protein-protein interactions (PPIs). Due to the difficulty in predicting cyclopeptide conformations in solution, the de novo design of bioactive cyclopeptides remains significantly challenging. In this study, we used the combination of conformational analyses and molecular docking studies to design a new cyclopeptide inhibitor of the interaction between the human tumour necrosis factor alpha (TNF $\alpha$ ) and its receptor TNFR-1. This interaction is a key in mediating the inflammatory response to tissue injury and infection in humans, and it is also an important causative factor of rheumatoid arthritis, psoriasis and inflammatory bowel disease. The solution state NMR structure of the cyclopeptide was determined, which helped to deduce its mode of interaction with TNF $\alpha$. TNF $\alpha$ sensor cells were used to evaluate the biological activity of the peptide.
\end{abstract}

Keywords: cyclic peptides; NMR structure; drug design; protein-protein interaction

\section{Introduction}

Tumour necrosis factor alpha $(\mathrm{TNF} \alpha)$ is a pleiotropic inflammatory cytokine produced and secreted mainly by macrophages, which can also be produced by many other cells, for instance, CD4+ lymphocytes, neutrophils, NK cells and mast cells [1]. TNF $\alpha$ plays an important role in the pathogenesis of many chronic inflammatory diseases and its inhibition has been shown to be an effective approach for therapy of rheumatoid arthritis, psoriatic arthritis, ankylosing spondylitis, psoriasis and inflammatory bowel disease [2]. The systemic inflammatory effects of TNF $\alpha$ are caused by its soluble form, which exists as a homo-trimeric complex of 17-kDa subunits. It binds to two different receptors: TNF Receptor-1 (TNFR-1), also known as [p55 (CD120a)], and TNF Receptor-2 (TNFR-2) [or p75 (CD120b)], to which TNF $\alpha$ binds with relatively higher affinity compared to TNFR-1 [3].

Binding of either TNFR-1 or 2 to their ligand induces the receptor's trimerisation. Both receptors bind TNF $\alpha$, with TNFR-1 being constitutively expressed in all cells, while TNFR-2 is inducibly regulated mainly in haematopoietic and endothelial cells $[4,5]$. The TNF $\alpha$-mediated clustering of TNFR-1 initiates the signalling of pathways that lead to both apoptosis (through the caspase cascade) and cell activation (through NF-kB) [6]. The NF-kB activation pathway following TNF $\alpha$ binding also 
induces pro-inflammatory cytokines like IL-4 and IL-8, responsible for the extensive tissue damage seen in many chronic inflammatory diseases [7].

Small linear peptides (8-10 amino acids) are not appropriate as mimetics of the defined secondary structures found in proteins, due to their intrinsic conformational flexibility. By contrast, the structural rigidity of cyclic peptides makes them good mimetics of the protein conformational epitopes that lead to interactions with proteins and ligands [8]. A common strategy to rigidify peptide structures is by cyclisation, which could be via disulphide bridge formation or amide bond formation between $\mathrm{N}$ - and $\mathrm{C}$ - termini. $\mathrm{N}$ - to $\mathrm{C}$ - cyclisation has the advantage that it usually leads to fewer rotatable bonds when compared to disulphide bridge formation. Therefore, $N$ - to $C$ - cyclisation usually results in more rigid and less flexible conformers [9].

A range of biologics targeting TNF $\alpha$ have been licensed for the treatment of various inflammatory diseases, such as rheumatoid arthritis and Crohn's disease [10]. Although these agents have high potency and specificity, they are limited by their high production costs and potential immunogenicity. For instance, large molecule biologics like infliximab have been associated with development of infusion reaction (antigenicity) despite their high selectivity for $\mathrm{TNF} \alpha$ [11]. Also, their large molecular weight and low oral stability means their administration is only feasible through injection [12]. Several small molecule synthetic inhibitors of TNF $\alpha$ are at different stages of pre-clinical and clinical development. Thalidomide was the first to be developed and it inhibits TNF $\alpha$ production by promoting TNF $\alpha$ mRNA degradation in stimulated monocytes [13]. This was followed by the discovery of other classes of inhibitors targeting p38 MAP kinase, which controls TNF $\alpha$ production, TNF $\alpha$ converting enzyme (TACE), and the mRNA coding for TNF $\alpha$. The majority of these agents exhibited toxicities related to their ability to cross the blood-brain barrier or by inhibition of liver cytochrome P450 enzyme [14]. Generally, the molecular size and lipophilicity of peptides determines their ability to cross the physical and enzymatic barriers of the brain [15]. Peptide cyclisation as a means of overcoming these two different types of barriers has only been successful with small opioid cyclopeptides (tetramers) possessing a $\beta$-turn [16].

Small molecule with anti-TNF $\alpha$ activity with compact 3D conformations containing trifluoromethylphenyl indole and chromone moieties have previously been designed. These compounds bind with high affinity $\left(\mathrm{IC}_{50}=13 \mu \mathrm{M}\right)$ to a hydrophobic binding pocket formed by six tyrosine residues (Y59, Y119 and Y151 from chain A and B) at the interface of TNF $\alpha$ dimer [17]. Alternative binding pockets that bind small molecules have also been identified from the predicted TNF $\alpha$-TNFR1 complex and these involve the residues H66, L67 and L71 of TNFR1 and residues R82, F90 and F127 in TNF $\alpha$ [18]. Recently, a small molecule benzimidazole derivative (UCB-6876) has been discovered, a co-crystal structure of UCB-6876 with TNF $\alpha$ resulted in a change in the spatial arrangement of the TNF $\alpha$ trimer and a loss of its 3-fold symmetry. This compound was also found to occupy the centre of the TNF $\alpha$ trimer filling a hydrophobic binding pocket involving chain A (Y59), chain B (L57, Y119) and chain C (Y59, Y151) [19].

\section{Results and Discussion}

In an attempt to discover improved anti-TNF $\alpha$ therapeutics, we designed a cyclic peptide that could directly inhibit the TNF $\alpha$-TNFR1 interaction and have potentially fewer side effects than the small molecule inhibitors and biologics mentioned above. This was achieved by producing a cyclic peptide with higher target specificity compared to small molecules and low potential of immunogenicity when compared with biologics. Protein loops are often involved in the biomolecular recognition of proteins [20]. Loop peptidomimetics have previously been introduced as a new class of bioactive agents. The cyclic peptide cyclo-GCRLYGFKIHGCG derived from the regulatory subunit (CK2 $\beta)$ of protein kinase 2 which inhibits the interaction with the associated catalytic subunit and is used for cancer therapy [21]. Another example is the macrocyclic peptidomimetic MCP-1, which is an inhibitor of the menin-MLL protein-protein interaction involved in leukemogenesis [22]. 
Structure-based design of exocyclic peptidomimetic inhibitors of TNF $\alpha$ prepared by Takasaki and colleagues provided a good starting point to develop PPI inhibitors [23]. The two TNFR-1 binding sites (WP8 and WP9) were known from the structural information available for the TNF $\beta / T N F R-1$ complex (Figure 1A) [24]. The importance of the WP5 binding site was inferred from the light chain sequences of several TNF $\alpha$ neutralising antibodies which have been shown to contribute to TNFR-1 binding. This data was further supported by the structural homology of the modelled light chain structure (CDR1) of anti-TNF $\alpha$ with the WP5 site [25].
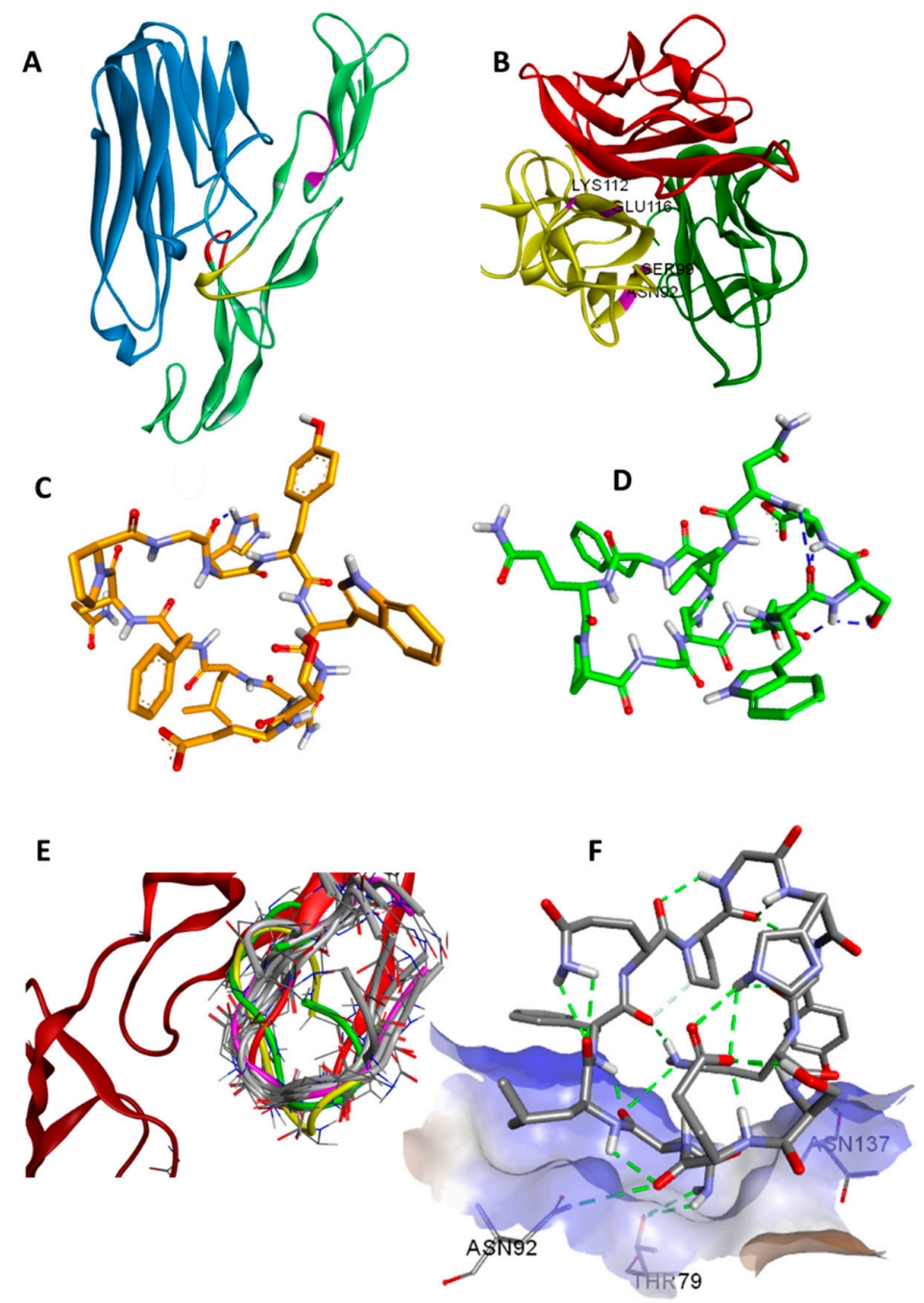

Figure 1. Modelling of the inhibition of TNF $\alpha$-TNFR1 interaction. (A) This figure shows the different binding sites of TNFR1 based on the available crystal structure of TNF $\beta / T N F R-1$ complex [PDB: 1TNR]. The TNF $\beta$ structure (blue) bound to TNFR-1 (green) with highlighted 3 TNFR1 binding sites, WP5 (magenta), WP8 (yellow) and WP9 (red). (B) 3D view of TNF $\alpha$ homo-trimer (PDB: 1TNF) showing residues N92, S99, K112 and E116 (magenta) at the interface that are important for the formation of the $\mathrm{TNF} \alpha$ bioactive complex. The lowest energy NMR structures of $\mathbf{1}$ are clustered into two main groups, a major group of seven structures, in which $(\mathbf{C})$ is the lowest energy conformation and a minor group of three structures in which (D) is the lowest conformation in the cluster. (E) illustrates structural similarity between different structures of $\mathbf{1}$ and WP9 domain. Aligned and superimposed docking poses and NMR structures of $\mathbf{1}$ against the WP9 loop of TNFR-1 are shown in red to illustrate their structural similarity. Docking pose 6 is shown in purple, and major and minor NMR structures are coloured in yellow and green, respectively. (F) WP9 loop peptidomimetic 1 docked to TNF $\alpha$ (PDB: 1TNF). The interaction involves four hydrogen bonds with N137, N92 and T79 residues of TNF $\alpha$; details can be found in Table S1. 
The design of a new anti-TNF $\alpha$ cyclic peptide 1 (Figure 2) was achieved by extending the 5 residues (WSENL) of the WP9 loop used to design WP9QY (Figure 2) to the 9 residues [105 HYWSENLFQ 113] which were cyclised head to tail via a proline-glycine linker to help stabilise the loop structure in an 11mer cyclic peptide; shown in (Table 1). This cyclic peptide showed enhanced binding to $\mathrm{TNF} \alpha$ evaluated by molecular docking (Table S1). The anti-TNF $\alpha$ activity of this new macrocyclic peptidomimetic of the WP9 binding site 1 in comparison with the known peptide WP9QY (purchased from Almac, Craigavon, UK) was determined by an in vitro cell-based assay [26]. The corresponding linear peptide of $\mathbf{1}$ was not evaluated because of the potential for off target binding due to the high conformational flexibility of linear peptides.

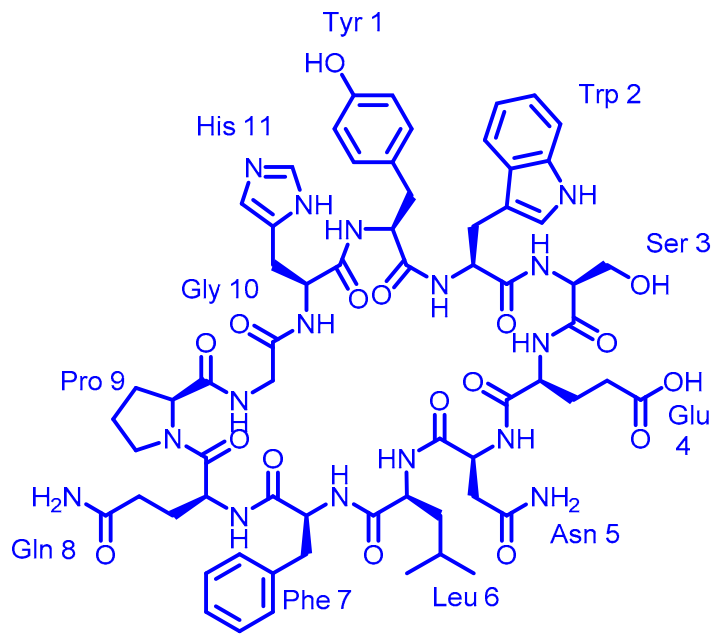

1

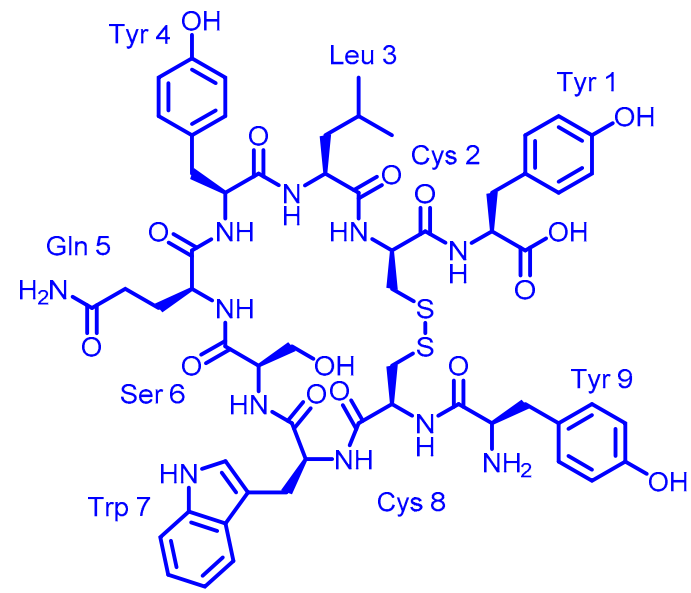

WP9QY

Figure 2. The chemical structure of the cyclic peptides 1 and WP6QY.

Table 1. Sequence comparison of original WP9 loop and anti-TNF $\alpha$ peptidomimetics.

\begin{tabular}{cc}
\hline Peptidomimetics & Sequence \\
\hline Original WP9 Loop & HYWSENLFQ \\
1 & HYWSENLFQP \\
WP9QY & YCWSQYLCY \\
\hline
\end{tabular}

A Monte Carlo search of the conformational space of $\mathbf{1}$ was performed to provide candidate structures for subsequent protein-ligand docking so as to avoid the docking procedure being biased by a single low-energy input structure. The structures obtained in this way were then docked to TNF $\alpha$ resulting in docking scores of around $-5 \mathrm{kcal} / \mathrm{mol}$ as shown in the Supplementary Material, Table S1. Docking results showed that 1 interacts mainly with four residues of TNF $\alpha$, namely N92, S99, K112 and E116, in the WP9 site. These residues were found to also mediate the interaction at the interface between TNF $\alpha$ monomers during the spontaneous polymerisation as observed in the crystal structure PDB: 1TNF (Figure 1B) [27]. Consequently, this might suggest an additional mechanism of TNF $\alpha$ inhibition by $\mathbf{1}$ which occurs by disrupting the formation of the biologically active homo-trimer of TNF $\alpha$.

The homo-multimerisation mechanism was first shown to be biologically relevant to the anti-TNF $\alpha$ activity of suramin, a polysulphonated naphthylurea which has been used previously to treat trypanosomiasis and onchocerciasis. Deoligomerisation of TNF $\alpha$ by suramin was shown by measuring 
the cell-bound radioactivity of cultured K562 cells incubated with ${ }^{125}$ I-labelled TNF $\alpha$ in the presence or absence of suramin [28]. Modelling of a suramin structural analogue bound to TNF $\alpha$ has led to prediction of the residues involved in the interaction. These include K112 and E116 which have been shown to interact with $\mathbf{1}$ as well as other residues including T72, K98 and R103 [29].

The synthesis of $\mathbf{1}$ was performed using a Fmoc-based SPPS protocol with a cyclisation yield of $33.1 \%$ at $98.4 \%$ purity. The chemical structure of 1 was confirmed by MS/MS and 2D NMR experiments (Supplementary Materials). NMR experiments were carried out in methanol- $d_{3}$ due to the low solubility of $\mathbf{1}$ in water. The three-dimensional NMR structure of $\mathbf{1}$ was determined by NOE-restrained molecular dynamics (27 NOE restraints) in which the lowest energy structures were found to be clustered into two groups (A and B) with 7 converged structures in the main group (A) and 3 in a minor group (B). The RMSD of the aligned backbones of the best structure in each group was $3.05 \AA$. The data showing detailed chemical analysis can be found in the Supplementary Materials. The lowest energy NMR structure in each cluster are shown in (Figure 1C,D).

A molecular similarity study of WP9 loop of TNFR-1 with NMR structures and docking poses of $\mathbf{1}$ was performed by alignment and superimposition of backbone atoms (Table 2, Figure 1E). The structural resemblance observed between the WP9 loop and the best docking pose (conformation 6) can be seen from the low RMSD value (backbone) of $2.09 \AA$ observed. This might suggest a mechanism of inhibition for $\mathbf{1}$ in which $\mathbf{1}$ binds to nearby residues in the WP9 binding site of TNF $\alpha$ and abolish the TNFR-1 interaction (Figure 1F). Furthermore, the lowest energy NMR structure of the main cluster (structure A) adopts a similar conformation to the WP9 loop of TNFR-1 (RMSD $=2.68$ ) and again suggesting an analogous binding mode to WP9QY. However, the polarity of the solvent used for NMR could also contribute to the observed difference in conformation [30].

Table 2. RMSDs for aligned and superimposed docking poses and NMR structures of $\mathbf{1}$ with reference to WP9 loop.

\begin{tabular}{cc}
\hline Structure & $\begin{array}{c}\text { RMSD }(\AA) \\
\text { (Main Chain) }\end{array}$ \\
\hline WP9 domain of TNFR-1 & Reference \\
Docking pose 6 & 2.09 \\
Docking pose 5 & 2.27 \\
Docking pose 2 & 2.44 \\
NMR structure A & 2.68 \\
Docking pose 4 & 2.71 \\
Docking pose 3 & 2.88 \\
NMR structure B & 3.50 \\
Docking pose 1 & 4.10 \\
\hline
\end{tabular}

A biological assay using a TNF $\alpha$ sensor cell (HEK-Blue TNF $\alpha$ cells, InvivoGen, Toulouse, France) was used to evaluate the anti-TNF $\alpha$ activity of 1 . In the assay, the cells are transfected with a secretory alkaline phosphatase reporter gene which is downstream of the NF-kB promoter and expressed in response to TNF $\alpha$ receptor activation. The alkaline phosphatase activity was then quantified by measuring the absorbance $(\lambda=620 \mathrm{~nm})$ of coloured substrate. For each assay, approximately $5 \times 10^{4}$ cells were seeded in each well of a 96 well flat-bottomed cell culture plate and incubated for $24 \mathrm{~h}$ with $1 \mathrm{ng} / \mathrm{mL}$ of recombinant human TNF $\alpha$ and different concentrations of both $\mathbf{1}$ and WP9QY in duplicates. Activation of HEK-Blue TNF $\alpha$ cells by $1 \mathrm{ng} / \mathrm{mL}$ of human TNF $\alpha$ (InvivoGen) in the presence and absence of anti-hTNF $\alpha$ antibody (InvivoGen) were used as positive and negative controls in the anti-TNF $\alpha$ assay (Figure 3). This assay was used as a direct measure of TNF $\alpha$ inhibition effect on cells, while the affinity of TNF $\alpha$ binding was evaluated by molecular docking results. 


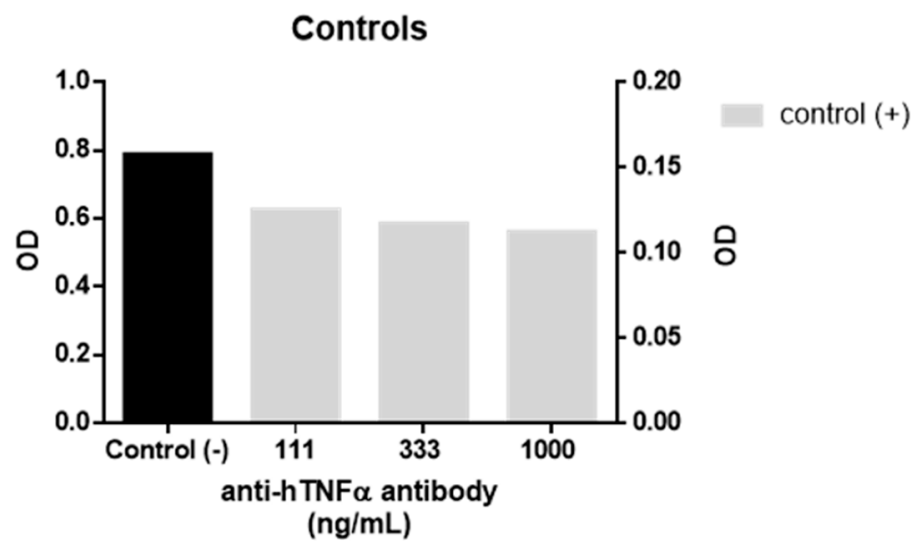

Figure 3. Controls used in $\mathrm{TNF} \alpha$ assay as a measure of HEK-Blue cells response to TNF $\alpha$. Negative control response to TNF $\alpha$ was used to normalise inhibitors' response to inhibition (\%). Anti-hTNF $\alpha$ antibody was used as positive control with significant difference in response following $\mathrm{T}$ test $(P<0.0001)$. Error bars are not visible due to the small size of the calculated standard errors.

A dose-response curve for TNF $\alpha$ inhibition by both 1 and WP9QY was generated by normalising the absorbance readings at $620 \mathrm{~nm}$ against dose to percentage. This resulted in $\mathrm{IC}_{50}$ of $133.7 \mu \mathrm{M}$ (by extrapolation) and of $121.7 \mu \mathrm{M}$ for 1 and WP9QY, respectively (Figure 4). In this assay, the inhibition of $\mathrm{TNF} \alpha$ activity by $35 \%$ is achieved by $117.4 \mu \mathrm{M}$ and $97.2 \mu \mathrm{M}$ for $\mathbf{1}$ and WP9QY respectively. This result contrasts with those of Takasaki and co-workers, where the same level of TNF $\alpha$ inhibition was reached by approximately $2.5 \mu \mathrm{M}$ of WP9QY when tested by using U937 cells in a flow cytometric assay [23]. Their flow cytometric assay measures anti-TNF $\alpha$ activity as was determined by inhibition of anti-TNF receptor antibody binding. Bound anti-TNF receptor antibody was then measured by its binding to fluorescein-labelled secondary antibody which does not represent direct interaction between TNF $\alpha$ and its receptor, whereas the assay used here quantifies $\mathrm{TNF} \alpha$ response directly.

TNF $\alpha$ inhibition assay

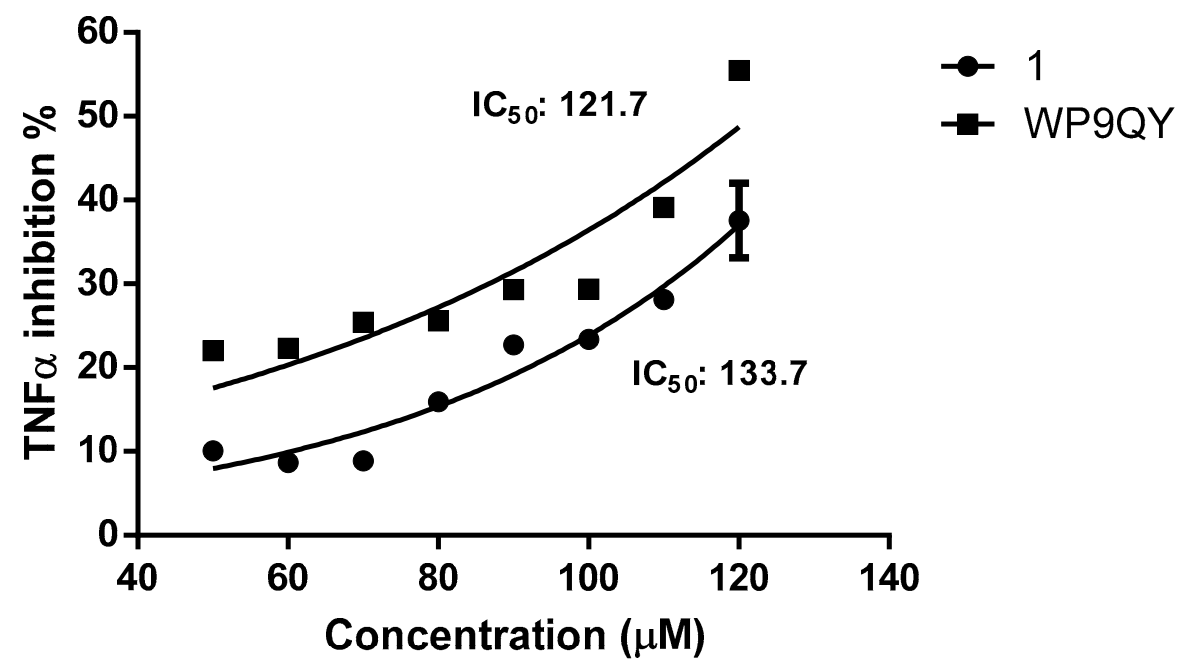

Figure 4. Dose-response curve of anti-TNF $\alpha$ activities of $\mathbf{1}$ and WP9QY. This assay was performed with one duplicate, and the error bar represent standard error. Non-linear regression was used to fit the curve to the measured data points. While measurements for $\mathbf{1}$ are well-fit, the WP9QY data shows slight deviations from those expected, this may be due to a different mode of action.

The assay used in this study is considered more specific for TNF $\alpha$ and measures TNF $\alpha$ activity directly and therefore provides more accurate results. Furthermore, the use of reporter gene inducible 
by TNF $\alpha$ gives more evidence as to whether the peptide binding would have agonistic or antagonistic effects downstream of the TNF $\alpha$ signalling pathway. Peptides were dissolved in DMSO and solutions were diluted with the cell culture media so the final concentration of DMSO is $1 \%$. Blank experiments with $1 \%$ DMSO were carried out. The difference in $\mathrm{IC}_{50}$ between 1 and WP9QY reported here could also be attributed to a different mode of action of $\mathbf{1}$ such as deoligomerisation of TNF $\alpha$ homo-trimer by 1 in which the binding to TNF $\alpha$ take place in 1:3 ratio with WP9QY binding stoichiometrically to block TNFR-1 interaction of the oligomer. This alternative mode of action (deoligmerisation) was proposed based on our docking results (Table S1), which shows the interaction of 1 with TNF $\alpha$ residues N92, S99, $\mathrm{K} 112$ and E116. These are key residues mediating interfacial interaction between TNF $\alpha$ monomers to form the biologically active trimer as illustrated in Figure 1B.

An MTT assay (Figure 5) showed no significant cytotoxicity to HEK-Blue TNF $\alpha$ cells at the concentration used to test anti-TNF $\alpha$ activity of both 1 and WP9QY. Therefore, this can be used as preliminary data for further biological evaluations.

\section{HEK-TNF $\alpha$ cells viability}

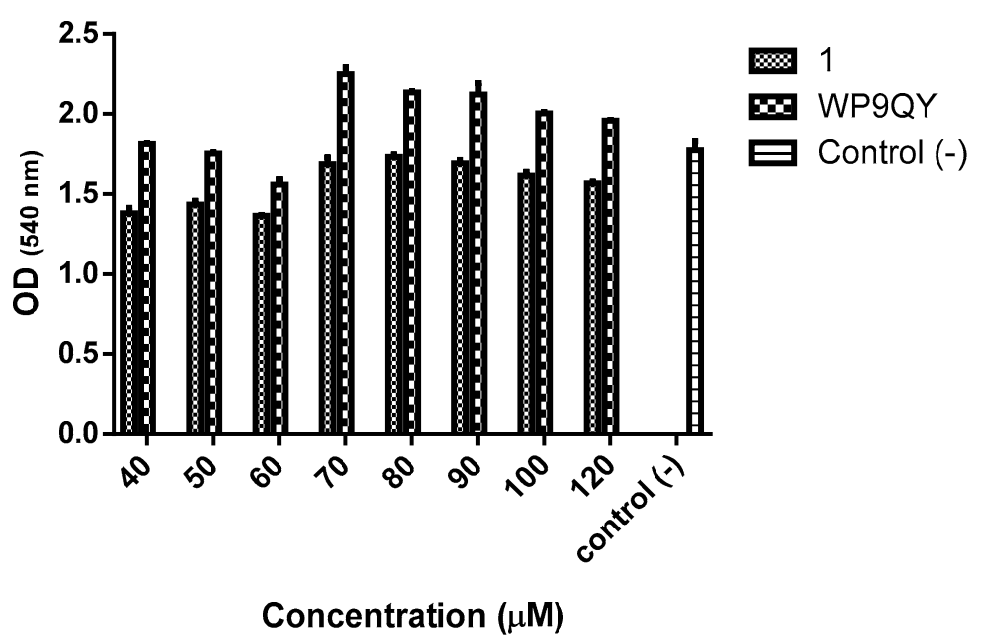

Figure 5. MTT assay of HEK-Blue TNF $\alpha$ cells in the presence of 1 and WP9QY. Optical density (OD) readings at $540 \mathrm{~nm}$ correspond to formazan levels formed by viable cells after incubation with 1 and WP9QY for $24 \mathrm{~h}$. This assay was performed with one duplicate, and the error bars show standard error.

\section{Materials and Methods}

Fmoc amino acid derivatives, coupling reagents (HBTU, HATU and HOBt), preloaded chlorotrityl resin (H-Gly 2-ClTrt), sym-collidine, trifluoroacetic acid (TFA), dichloromethane (DCM) and acetonitrile (HPLC grade) were purchased from Merck (Feltham, UK). N,N-dimethylformamide (DMF), piperidine, 1,1,1,3,3,3-Hexafluoro-2-propanol (HFIP), N,N-diisopropylethylamine (DIEA) and triisopropylsilane (TIS) were supplied by Alfa Aesar (Lancashire, UK).

A conformational search for thermally accessible structures of $\mathbf{1}$ was done using the Tinker molecular modelling package [31]. A set of initial cyclic peptide structures for use in the following protein-ligand docking studies was generated by Tinker's monte Monte-Carlo program using the AMBER99 force field. 5000 steps of Cartesian moves and maximum atom displacement of $3 \AA$ (default) was used. The temperature was set to $500 \mathrm{~K}$ and a maximum RMS gradient for truncated Newton minimisation of 0.01 (default) used. Final potential energies for each optimised conformation was then calculated in $\mathrm{kcal} / \mathrm{mol}$ using Tinker's analyze executable. The Boltzmann distribution of conformational ensemble obtained in this way was determined by calculating the Boltzmann factor for each structure by the following equation:

$$
B F=\exp \left(-\frac{E}{R T}\right)
$$


where $B F$ is the Boltzmann factor, $E$ is the total potential energy in $\mathrm{kJ} / \mathrm{mol}, R$ is the gas constant $(8.314 \mathrm{~J} / \mathrm{K} / \mathrm{mol})$, and $T$ is the temperature in kelvin. The ratios of Boltzmann factors for all selected conformations relative to the highest energy conformation were then calculated. Structural comparison by molecular overlay (all atoms) for the resulting conformations was carried out by determining root mean square deviations (RMSDs) in Angstroms for each structure with reference to the lowest energy conformation. This was done in Discovery Studio Visualizer and all conformations of $\mathbf{1}$ were docked to TNF $\alpha$ using AutoDock Vina.

Side chain-protected linear peptide sequence of $\mathbf{1}$ was synthesised manually using solid phase peptide synthesis strategy (SPPS). H-Gly 2-ClTrt resin (loading of $1.1 \mathrm{mmol} / \mathrm{g}$ and $0.3 \mathrm{~g}$ ) was first swelled in DMF for $20 \mathrm{~min}$, and the construction of the peptide sequence was done through cycles of Fmoc deprotection of attached amino acids and HBTU coupling of the next amino acid in the sequence. Fmoc deprotection was carried out using $20 \%$ piperidine while coupling was done by mixing molar ratio of amino acid:HBTU:HOBt:DIEA:preloaded resin of 3:3:3:6:1 rotated for $1 \mathrm{~h}$ at room temperature. Reaction progress was monitored by LC-MS. Completed linear peptide sequence was cleaved from the solid support with 20\% HFIP in DCM, dried under vacuum and used for cyclisation reactions. Macrocyclisation of synthesised linear peptide was carried in DMF under dilution condition $(0.1 \mathrm{mM})$ using 1.5 equivalents of HATU, HOBt and sym-collidine slowly added to vigorously stirred peptide solution at room temperature for $24 \mathrm{~h}$. Crude reaction product was then dried and deprotected using a mixture of 95\% TFA, 2.5\% TIS and 2.5\% water [32]. Product obtained was then purified by reverse-phase HPLC with 5\% to $100 \%$ gradient of acetonitrile/water on C-18 column (ACE, HiChrom, $250 \mathrm{~mm} \times 10 \mathrm{~mm}$ i.d) followed by lyophilisation. Purified cyclic peptide was then analysed by HPLC, LC-MS and 2D NMR experiments.

Three-dimensional NMR structure of $\mathbf{1}$ was calculated in methanol- $d 3$ solution using NOE-restrained molecular dynamics. The experimental NOE restraint values were directly used in calculation rather than distances. Here we used NOE restraints calculated from NOESY cross-peak volume with reference to known distances in the molecule. Cross-peak volumes were calculated using MestReNova software and NOE restraints by the following equation:

$$
r_{i j}=r_{r e f}\left(\frac{\alpha_{r e f}}{\alpha_{i j}}\right)^{\frac{1}{6}}
$$

where, $r_{i j}$ and $\alpha_{i j}$ are distance and peak volume demanded respectively, and $r_{r e f}$ and $\alpha_{\text {ref }}$ represent distance and peak volume of reference, respectively. The structure calculations were carried out using XPLOR-NIH by first generating random structures of the cyclic peptide. Then, simulated annealing was performed by heating the molecules to $3500 \mathrm{~K}$ and slowly cooled down to $100 \mathrm{~K}$ through 60,000 cooling steps. During simulated annealing, the NOE restraints were used to drive the conformational ensemble of cyclic peptides. The trans configuration of residue P9 was also taken into consideration during the calculations. This was determined by a low ${ }^{13} \mathrm{C}$ chemical shift difference of $4.27 \mathrm{ppm}$ between $C \beta$ and $C \gamma[30]$.

TNF $\alpha$ sensor cells (HEK-Blue) were grown in Dulbecco's Modified Eagle's medium (DMEM) containing $4.5 \mathrm{~g} / \mathrm{L}$ glucose and supplemented with $10 \%[v / v]$ heat-inactivated foetal bovine serum, $2 \mathrm{mM}$ L-glutamine, $100 \mu \mathrm{g} / \mathrm{mL}$ normocin, $50 \mathrm{U} / \mathrm{mL}$ penicillin and $50 \mu \mathrm{g} / \mathrm{mL}$ streptomycin. Selective antibiotics added to the culture medium include $100 \mu \mathrm{g} / \mathrm{mL}$ zeocin and $1 \mu \mathrm{g} / \mathrm{mL}$ puromycin and avoided in initial cultures (first 2 passages). Maintenance cultures were kept in T-75 cell culture flasks and incubated in humidified incubator with $5 \%[v / v] \mathrm{CO}_{2}$ at $37{ }^{\circ} \mathrm{C}$. HEK-Blue cultures reaching $70 \%-80 \%$ confluency were passaged by first washing and detaching the cells gently with Dulbecco's phosphate buffered saline. Cells were then pelleted by centrifugation at $1200 \mathrm{rpm}$ for $5 \mathrm{~min}$. Supernatant was discarded and cell pellets resuspended in fresh media and used in different assays.

The Vybrant ${ }^{\circledR \circledR}$ MTT assay (Thermo Fisher Scientific) was performed following the manufacturer protocol. In this assay, cell permeable tetrazolium dye (yellow) was oxidised by mitochondrial oxidases 
in viable cells to yield the water-insoluble formazan (purple) after incubation with HEK-TNF $\alpha$ cells. Formazan was then solubilised and quantified by measuring the UV absorbance at $540 \mathrm{~nm}$.

\section{Conclusions}

The rational design strategy used in this study led to the discovery of a new moderate inhibitor of TNF $\alpha$-TNFR-1 interaction. This cyclic peptide will be used at starting point for the development of more effective. The modelling steps, as well as the study of NMR solution structure, helped in suggesting a mode of action for $\mathbf{1}$ by correlating the structural similarity between $\mathbf{1}$ and the WP9 loop in TNFR-1. The $N$ - to $C$ - macrocyclic structure of $\mathbf{1}$ may be expected to confer better chemical stability and bioactivity compared to the disulphide bridged peptidomimetic (WP9QY).

Supplementary Materials: The following are available online, containing data for molecular modelling, LC-MS and NMR analyses and further details about of TNF $\alpha$ sensor cells.

Author Contributions: Conceptualization, W.E.H.; Data curation, M.I.; Formal analysis, M.I., B.F.M., G.S.T., L.T. M.J. and W.E.H.; Funding acquisition, M.I., M.J. and W.E.H.; Methodology, M.I.; Project administration, W.E.H.; Supervision, B.F.M., G.S.T., L.T., M.J. and W.E.H.; Writing—original draft, M.I.; Writing—review \& editing, B.F.M., G.S.T., L.T., M.J. and W.E.H. All authors have read and agreed to the published version of the manuscript.

Funding: This project was supported by grants from the University of Aberdeen (Elphinstone PhD scholarship, M.I.), ERC (No. 339367, M.J.), EPSRC fellowship (EP/S027246/1, W.E.H.). B.F.M. funded by the Portuguese Fundação para a Ciência e a Tecnologia (projects CENTRO-01- 0145-FEDER-000014, 2017-2020 and POCI-01-0145-FEDER-032229) and the Donostia International Physics Centre (San Sebastián, Spain). The Coimbra Chemistry Centre is supported by the Fundação para a Ciência e a Tecnologia, through the Project PEstOE/QUI/UI0313/2014 and POCI-01-0145-FEDER-007630.

Acknowledgments: The authors would like to thank the Aberdeen Proteomics Facility and the Aberdeen School of Natural and Computing Sciences MS and NMR Facility for LC-MS and NMR analysis. We also want to acknowledge Prof. Robert Barker and Charlotte Lennon for providing access to their biological testing facility.

Conflicts of Interest: The authors declare no conflict of interest.

\section{References}

1. Carswell, E.; Old, L.J.; Kassel, R.; Green, S.; Fiore, N.; Williamson, B. An Endotoxin-Induced Serum Factor that Causes Necrosis of Tumors. Proc. Natl. Acad. Sci. USA 1975, 72, 3666-3670. [CrossRef]

2. Esposito, E.; Cuzzocrea, S. TNF-Alpha as a Therapeutic Target in Inflammatory Diseases, Ischemia-Reperfusion Injury and Trauma. Curr. Med. Chem. 2009, 16, 3152-3167. [CrossRef] [PubMed]

3. Locksley, R.M.; Killeen, N.; Lenardo, M.J. The TNF and TNF Receptor Superfamilies: Integrating Mammalian Biology. Cell 2001, 104, 487-501. [CrossRef]

4. Tartaglia, L.A.; Pennica, D.; Goeddel, D. Ligand Passing: The 75-kDa Tumor Necrosis Factor (TNF) Receptor Recruits TNF for Signaling by the 55-kDa TNF Receptor. J. Biol. Chem. 1993, 268, 18542-18548. [PubMed]

5. Arnott, C.H.; Scott, K.A.; Moore, R.J.; Robinson, S.C.; Thompson, R.G.; Balkwill, F.R. Expression of both TNF-A Receptor Subtypes is Essential for Optimal Skin Tumour Development. Oncogene 2004, $23,1902$. [CrossRef] [PubMed]

6. Vandevoorde, V.; Haegeman, G.; Fiers, W. Induced Expression of Trimerized Intracellular Domains of the Human Tumor Necrosis Factor (TNF) p55 Receptor Elicits TNF Effects. J. Cell Biol. 1997, 137, 1627-1638. [CrossRef]

7. Lawrence, T. The Nuclear Factor NF-kappaB Pathway in Inflammation. Csh. Perspect. Biol. 2009, 1, a001651.

8. Bach, A.C.; Espina, J.R.; Jackson, S.A.; Stouten, P.F.; Duke, J.L.; Mousa, S.A.; DeGrado, W.F. Type II 'to Type I B-Turn Swap Changes Specificity for Integrins. J. Am. Chem. Soc. 1996, 118, 293-294. [CrossRef]

9. Jackson, S.; DeGrado, W.; Dwivedi, A.; Parthasarathy, A.; Higley, A.; Krywko, J.; Rockwell, A.; Markwalder, J.; Wells, G. Template-Constrained Cyclic Peptides: Design of High-Affinity Ligands for GPIIb/IIIa. J. Am. Chem. Soc. 1994, 116, 3220-3230. [CrossRef]

10. Taylor, P.C.; Feldmann, M. Anti-TNF Biologic Agents: Still the Therapy of Choice for Rheumatoid Arthritis. Nat. Rev. Rheumatol. 2009, 5, 578-582. [CrossRef]

11. Lecluse, L.; Piskin, G.; Mekkes, J.; Bos, J.; De Rie, M. Review and Expert Opinion on Prevention and Treatment of Infliximab-related Infusion Reactions. Br. J. Dermatol. 2008, 159, 527-536. [CrossRef] [PubMed] 
12. Murdaca, G.; Spanò, F.; Contatore, M.; Guastalla, A.; Penza, E.; Magnani, O.; Puppo, F. Immunogenicity of Infliximab and Adalimumab: What is its Role in Hypersensitivity and Modulation of Therapeutic Efficacy and Safety. Expert Opin. Drug Saf. 2016, 15, 43-52. [CrossRef] [PubMed]

13. Sampaio, E.P.; Sarno, E.N.; Galilly, R.; Cohn, Z.A.; Kaplan, G. Thalidomide Selectively Inhibits Tumor Necrosis Factor Alpha Production by Stimulated Human Monocytes. J. Exp. Med. 1991, 173, 699-703. [CrossRef] [PubMed]

14. Palladino, M.A.; Bahjat, F.R.; Theodorakis, E.A.; Moldawer, L.L. Anti-TNF-A Therapies: The Next Generation. Nat. Rev. Drug Discov. 2003, 2, 736-746. [CrossRef]

15. Witt, K.A.; Gillespie, T.J.; Huber, J.D.; Egleton, R.D.; Davis, T.P. Peptide Drug Modifications to Enhance Bioavailability and Blood-Brain Barrier Permeability. Peptides 2001, 22, 2329-2343. [CrossRef]

16. Gudmundsson, O.; Jois, S.; Velde, D.V.; Siahaan, T.; Borchardt, R.; Wang, B. The Effect of Conformation on the Membrane Permeation of Coumarinic Acid-and Phenylpropionic Acid-based Cyclic Prodrugs of Opioid Peptides. J. Pept. Res. 1999, 53, 383-392. [CrossRef]

17. He, M.M.; Smith, A.S.; Oslob, J.D.; Flanagan, W.M.; Braisted, A.C.; Whitty, A.; Cancilla, M.T.; Wang, J.; Lugovskoy, A.A.; Yoburn, J.C.; et al. Small-Molecule Inhibition of TNF- $\alpha$. Science 2005, 310, 1022-1025. [CrossRef]

18. Chen, S.; Feng, Z.; Wang, Y.; Ma, S.; Hu, Z.; Yang, P.; Chai, Y.; Xie, X. Discovery of Novel Ligands for TNF- $\alpha$ and TNF Receptor-1 through Structure-Based Virtual Screening and Biological Assay. J. Chem. Inf. Model. 2017, 57, 1101-1111. [CrossRef]

19. O'Connell, J.; Porter, J.; Kroeplien, B.; Norman, T.; Rapecki, S.; Davis, R.; McMillan, D.; Arakaki, T.; Burgin, A.; Fox III, D. Small Molecules that Inhibit TNF Signalling by Stabilising an Asymmetric Form of the Trimer. Nat. Commun. 2019, 10, 1-12. [CrossRef]

20. London, N.; Raveh, B.; Schueler-Furman, O. Druggable Protein-protein Interactions-from Hot Spots to Hot Segments. Curr. Opin. Chem. Biol. 2013, 17, 952-959. [CrossRef]

21. Laudet, B.; Barette, C.; Dulery, V.; Renaudet, O.; Dumy, P.; Metz, A.; Prudent, R.; Deshiere, A.; Dideberg, O.; Filhol, O. Structure-Based Design of Small Peptide Inhibitors of Protein Kinase CK2 Subunit Interaction. Biochem. J. 2007, 408, 363-373. [CrossRef] [PubMed]

22. Zhou, H.; Liu, L.; Huang, J.; Bernard, D.; Karatas, H.; Navarro, A.; Lei, M.; Wang, S. Structure-Based Design of High-Affinity Macrocyclic Peptidomimetics to Block the Menin-Mixed Lineage Leukemia 1 (MLL1) Protein-protein Interaction. J. Med. Chem. 2013, 56, 1113-1123. [CrossRef] [PubMed]

23. Takasaki, W.; Kajino, Y.; Kajino, K.; Murali, R.; Greene, M.I. Structure-based Design and Characterization of Exocyclic Peptidomimetics that Inhibit TNF $\alpha$ Binding to its Receptor. Nat. Biotechnol. 1997, 15, 1266-1270. [CrossRef] [PubMed]

24. Banner, D.W.; D’Arcy, A.; Janes, W.; Gentz, R.; Schoenfeld, H.; Broger, C.; Loetscher, H.; Lesslauer, W. Crystal Structure of the Soluble Human 55 Kd TNF Receptor-Human TNF $\beta$ Complex: Implications for TNF Receptor Activation. Cell 1993, 73, 431-445. [CrossRef]

25. Döring, E.; Stigler, R.; Grütz, G.; Von Baehr, R.; Schneider-Mergener, J. Identification and Characterization of a TNF $\alpha$ Antagonist Derived from a Monoclonal Antibody. Mol. Immunol. 1994, 31, 1059-1067. [CrossRef]

26. Saito, H.; Kojima, T.; Takahashi, M.; Horne, W.C.; Baron, R.; Amagasa, T.; Ohya, K.; Aoki, K. A Tumor Necrosis Factor Receptor Loop Peptide Mimic Inhibits Bone Destruction to the Same Extent as Anti-tumor Necrosis Factor Monoclonal Antibody in Murine Collagen-induced Arthritis. Arthritis Rheum. 2007, 56, 1164-1174. [CrossRef]

27. Eck, M.J.; Sprang, S.R. The Structure of Tumor Necrosis Factor-Alpha at 2.6 A Resolution. Implications for Receptor Binding. J. Biol. Chem. 1989, 264, 17595-17605.

28. Alzani, R.; Cozzi, E.; Corti, A.; Temponi, M.; Trizio, D.; Gigli, M.; Rizzo, V. Mechanism of Suramin-Induced Deoligomerization of Tumor Necrosis Factor Alpha. Biochemistry 1995, 34, 6344-6350. [CrossRef]

29. Mancini, F.; Toro, C.M.; Mabilia, M.; Giannangeli, M.; Pinza, M.; Milanese, C. Inhibition of Tumor Necrosis Factor-A (TNF-A)/TNF-A Receptor Binding by Structural Analogues of Suramin. Biochem. Pharmacol. 1999, 58, 851-859. [CrossRef]

30. Tabudravu, J.; Morris, L.A.; Kettenes-van den Bosch, J.J.; Jaspars, M. Wainunuamide, a Histidine-Containing Proline-Rich Cyclic Heptapeptide Isolated from the Fijian Marine Sponge Stylotella Aurantium. Tetrahedron Lett. 2001, 42, 9273-9276. [CrossRef] 
31. Ponder, J.W.; Richards, F.M. An Efficient Newton-like Method for Molecular Mechanics Energy Minimization of Large Molecules. J. Comput. Chem. 1987, 8, 1016-1024. [CrossRef]

32. Chatterjee, J.; Laufer, B.; Kessler, H. Synthesis of N-Methylated Cyclic Peptides. Nat. protoc. 2012, 7, $432-444$. [CrossRef] [PubMed]

Sample Availability: Samples of the compound $\mathbf{1}$ are available from the authors.

(C) 2020 by the authors. Licensee MDPI, Basel, Switzerland. This article is an open access article distributed under the terms and conditions of the Creative Commons Attribution (CC BY) license (http://creativecommons.org/licenses/by/4.0/). 